\title{
Impact of adopting different socioeconomic indicators in older adults' oral health research
}

Orlando Luiz do AMARAL JÚNIOR(a) Gabriele Rissotto MENEGAZZO(a) Maria Laura Braccini FAGUNDES(a) Fernanda TOMAZONI(a) (D) Jessye Melgarejo do Amaral GIORDANI(a)

(a) Universidade Federal de Santa Maria UFSM, Postgraduate Program in Dental Sciences, Santa Maria, RS, Brazil.

Declaration of Interests: The authors certify that they have no commercial or associative interest that represents a conflict of interest in connection with the manuscript.

\section{Corresponding Author:}

Jessye Melgarejo do Amaral Giordani

E-mail: jessyesm@hotmail.com

hitps://doi.org/10.1590/1807-3107bor-2021.vol35.0040

Submitted: June 26, 2020

Accepted for publication: October 22, 2020

Last revision: December 8, 2020
Abstract: This study aimed to evaluate the influence of choosing different socioeconomic status indicators in research regarding older adults' oral health. This is a cross-sectional study that analyzed baseline data from the Brazilian Longitudinal Study on Aging (ELSI-Brazil). The outcomes were edentulism $(\mathrm{n}=9,073)$ and self-reported oral health $(\mathrm{n}=9,365)$. The following socioeconomic indicators were assessed: individual income, per capita household income, and wealth index. Poisson regression analysis with robust variance was performed to estimate prevalence ratios (PR), with their respective 95\% confidence intervals (CI), after adjusting for socioeconomic and oral health behavior variables. Absolute inequality measures were also estimated. The individual income indicator was not statistically associated with the results after adjustments. When using per capita household income indicator, individuals in the richest quintile showed a 12\% lower prevalence of poor self-reported oral health [PR: 0.88 (CI: 0.78-0.98)], relative to the poorest, and there was no association with edentulism. When the wealth index was chosen, there was a $22 \%$ lower prevalence of edentulism [PR: 0.78 (CI: 0.64-0.94)] and 15\% lower prevalence of self-reported poor oral health [PR: 0.85 (CI: 0.78-0.93)] in individuals of the richest quintile, both relative to the poorest quintile. Regarding absolute inequality measures, for edentulism, the wealth index showed the highest absolute inequality. When considering self-reported oral health, per capita household income showed the greatest absolute inequality. Despite scientific challenges and the difficulty of socioeconomic indicator metrics, further investments in its development are critical to measure, promote, and improve population oral health.

Keywords: Income; Oral Health; Socioeconomic Factors.

\section{Introduction}

Social determinants of health (SDH) are specific characteristics of daily living that can affect individuals' health, like the circumstances in which people are born, grow up, live, work and grow old. ${ }^{1}$ Their use for population analysis in the context of public policies is essential because they encourage the confrontation of health inequalities.2,3 Poor 
oral health status is highlighted among the health conditions related to SDH, as it affects about four billion individuals worldwide. ${ }^{4}$ Poor oral health brings negative consequences for the individual's quality of life, leading to serious economic problems. ${ }^{4}$ Previous studies have shown that almost half of the global population has their oral health unfairly affected by unequal social conditions. ${ }^{5,6}$

Social conditions are important in shaping individual health behaviors encompassed by the common risk factor approach because resources favor access to favorable health circumstances. ${ }^{7}$ Like other health outcomes, oral diseases are standardized across the social hierarchy-a relationship known as the social gradient. Health status, behaviors, and access to oral health are determined mainly by social conditions. ${ }^{7,8}$ Therefore, oral health conditions are related to socioeconomic level across the population's socioeconomic gradient. ${ }^{9}$

Socioeconomic indicators are identified as strong single indicators of living standards in health research, occupying an intermediate position in the regulation of SDHs and acting upon the individual's health and well-being. ${ }^{10}$ These indicators are considered capable of facilitating access to healthcare through material and psychosocial pathways. ${ }^{11}$ Moreover, there are many studies using different socioeconomic indicators, such as per capita family income, ${ }^{12}$ wealth, ${ }^{13}$ and individual income, ${ }^{14}$ all of which differ from each other. Household and individual income have been the most used in health research, while wealth is an indicator that captures stock of economic reserves. ${ }^{15}$

The aforementioned socioeconomic indicators have been positively correlated with health outcomes, and the higher their levels, the better the individual's health. ${ }^{15,16}$ However, to our knowledge, no studies have assessed which economic indicators are more appropriate to identify scenarios with socioeconomic inequalities in the population's oral health. ${ }^{17}$ Therefore, this study aimed to evaluate the influence of using different socioeconomic status indicators (individual income, per capita household income, and wealth index) on older adults' oral health research.

\section{Methodology}

\section{Study design and population}

This cross-sectional study analyzed the baseline data obtained in the Brazilian Longitudinal Study of Aging (ELSI-Brazil). The ELSI-Brazil is a nationally representative population-based cohort study of people aged 50 years or older from 70 municipalities across all Brazilian regions. The baseline survey was conducted between 2015 and 2016, and it is part of an international network of large longitudinal studies on aging. This study was approved by the Brazilian National Research Ethics Committee (certificate of ethical appreciation presentation: 63725117.9.0000.5091). In addition, the participants signed an informed consent form. ${ }^{18}$ Moreover, the Strengthening the Reporting of Observational Studies in Epidemiology (STROBE) guidelines were followed to write the manuscript.

The ELSI-Brazil has a sample design with multiple selection stages, combining stratification of primary sampling units (municipalities), census tracts, and households. The sample was divided into four strata, with the first stratum comprising 4,420 municipalities and $\leq 26,700$ inhabitants, the second comprised 951 municipalities and 26,701-135,000 inhabitants, the third comprised 171 municipalities and 135,000750,000 inhabitants, and the fourth comprised 23 municipalities and $>750,000$ inhabitants. The sample for the first three strata (municipalities of up to 750,000 inhabitants) was selected in three stages. In the first stage, 18 municipalities were selected in the first stratum, 15 in the second, and 14 in the third. In the second stage, 8 census tracts were selected from each municipality, while households were selected from each census tract in the third stage. The sample for the fourth stratum, which included the largest municipalities, was selected in two stages, with 176 census tracts selected in the first stage and households selected in the second stage. All residents in the selected households aged 50 years and over were eligible for participation. More details can be found elsewhere. ${ }^{18}$

The sample size was estimated considering the following parameters: $5 \%$ standard error, $80 \%$ power, $95 \%$ confidence level, and 70\% lower odds of those 
with higher income to have poor self-reported oral health ${ }^{19}$ or $44 \%$ to have edentulism. ${ }^{13}$ Correction factors of 1.2 for effect design and $30 \%$ for non-response were applied to increase accuracy. Considering the two outcomes, the minimum sample size required was 4,389 participants. The final sample for edentulism was 9,073 individuals and 9,365 for self-reported oral health.

\section{Data collection}

Data collection was performed using a household questionnaire and an individual questionnaire answered by the selected participants. ${ }^{18}$

The outcomes of edentulism and self-reported oral health were collected using the following self-reported questions: "How many teeth do you have?" (none/ 1 to 9 teeth/10 to 19 teeth/20 or more teeth). Participants were categorized as edentulous (toothless) and toothed individuals. ${ }^{20}$ Self-reported oral health was collected using the question: "Do you think the health of your teeth and gums is: (very good/good/regular/ bad/very bad)?" Participants answers were dichotomized as "good" (very good/ good) and "poor" (fair/poor/very poor). ${ }^{21}$

Three common socioeconomic indicators were evaluated: individual income, per capita household income, and wealth index. Individual income was obtained by asking the amount of Brazilian reais (approximately USD 4 during the data gathering) received monthly. It was categorized into quintiles, from the poorest to the richest, as in previous studies. ${ }^{14}$ Per capita household income results (based on the total monthly gross household income divided by the number of residents) were also categorized into quintiles. ${ }^{22}$ The wealth index was based on the national population, using a multivariate statistical technique that transforms a set of original variables into another set of variables of equal values, called principal components. ${ }^{23}$ For its creation, information on the ownership of durable goods and housing characteristics was used: internet, television, DVD or VCR, cable TV, refrigerator, washing machine, dishwasher, dryer, computer, landline, mobile phone, microwave, air conditioning, motorcycle, car, house with a housekeeper, masonry wall, running water access, street access pavement, presence of bathroom, and family agglomeration (number of rooms in the house divided by the number of residents). These data were also categorized into quintiles, as in previous studies.13

The conceptual theoretical model of SDH for oral health was used to select possible confounding variables. ${ }^{7}$ Demographic and socioeconomic adjustment variables included self-reported sex (male/female), age (50-59 years, 60-69 years, and 70 years and older), ${ }^{13}$ race (categorized as white and non-white due to the low prevalence of non-white categories: black, brown, yellow, and indigenous), ${ }^{24}$ and education (categorized as 0 to 8 years-which comprises elementary education in Brazil-and 9 years or more). ${ }^{25}$

Oral health behavior measures included treatment need, use of dental services, and oral health habits. Need of dental services data were collected using the question "Do you think you currently need dental treatment?" (yes/no). The use of dental services was collected using the question "When did you last visit the dentist?" (less than one year ago/one year ago or more/never have been to the dentist). ${ }^{21}$ Oral health habits were assessed as follows: "Do you use a toothbrush to clean your mouth and teeth? Do you use toothpaste to clean your mouth and teeth? Do you use dental floss to clean your mouth and teeth?" Participants answered 'yes' or 'no'.

\section{Statistical analysis}

Data were analyzed using STATA 14.0 software. Because of the complex sample, it was necessary to use the sample weight to expand it and incorporate the design effect. Poisson regression models with robust variance were used to estimate the crude and adjusted prevalence ratios (PR), their respective 95\% confidence intervals $(95 \% \mathrm{CI})$, and $5 \%$ significance level. The associations between both outcomes and the three socioeconomic indicators were analyzed separately.

The observable absolute differences between individual income, per capita household income, and wealth index were also analyzed. The absolute inequality measure represents the absolute difference, in predicted values, of a health indicator between the most- and the least-favored individuals in terms of socioeconomic indicators. ${ }^{26}$ Thus, it is calculated as 
the difference, in percentage points (p.p), between the estimated values for the extreme groups of the variable (the richest quintile and the poorest one). ${ }^{27}$

\section{Results}

The ELSI-Brazil sample consisted of 9,412 individuals. The final sample for edentulism and self-reported oral health comprised 9,073 and 9,365 participants, respectively. Table 1 describes the population distribution and the dependent variables according to demographic, socioeconomic, and oral health behavioral variables. The sample was composed mostly of female (54\%) non-white (57.2\%) people aged 50-59 years $(47.6 \%)$ with less than eight years of formal education (73.1\%). Most

Table 1. Weighted Sample demographic characteristics, socioeconomic adjustment variables, and oral health behavior prevalence and crude prevalence ratios of edentulism and poor self-perception of oral health among older adults at baseline of the Brazilian Longitudinal Study of Aging.

\begin{tabular}{|c|c|c|c|}
\hline \multirow{2}{*}{ Variables } & Weighted & Edentulism & Poor self-reported oral health \\
\hline & $\%$ & Prevalence $(95 \% \mathrm{Cl})$ & Prevalence $(95 \% \mathrm{Cl})$ \\
\hline \multicolumn{4}{|l|}{ Sex } \\
\hline Female & 54.0 & 35.85 (33.3-38.5) & $41.8(39.9-43.7)$ \\
\hline Male & 46.0 & 22.31 (19.7-25.0) & $49.7(47.6-51.7)$ \\
\hline \multicolumn{4}{|l|}{ Age (years) } \\
\hline $50-59$ & 47.6 & $15.40(13.6-17.4)$ & $51.4(49.0-53.8)$ \\
\hline $60-69$ & 29,7 & $33.60(30.6-36.8)$ & $43.8(41.6-46.0)$ \\
\hline$\geq 70$ & 22,7 & $53.99(50.9-57.0)$ & $34.9(32.7-37.2)$ \\
\hline \multicolumn{4}{|l|}{ Race } \\
\hline White & 42.7 & $28.57(25.7-31.6)$ & $41.6(39.8-43.4)$ \\
\hline Non-white & 57,3 & $29.43(26.7-32.3)$ & $48.8(46.6-51.1)$ \\
\hline \multicolumn{4}{|c|}{ Own education (years of formal education) } \\
\hline $0-8$ & 73.1 & $36.40(33.7-39.2)$ & $46.3(44.4-48.3)$ \\
\hline$>8$ & 26.9 & $11.30(9.7-13.0)$ & $42.9(40.1-45.7)$ \\
\hline \multicolumn{4}{|l|}{ Need of treatment } \\
\hline No & 43.8 & $48.6(44.7-52.5)$ & $20.4(18.4-22.5)$ \\
\hline Yes & 56.2 & 14.2 (12.7-15.8) & $64.9(62.8-66.8)$ \\
\hline \multicolumn{4}{|l|}{ Use of dental services } \\
\hline Less than a year go & 32.6 & $11.3(10.0-12.7)$ & $43.9(41.8-46.1)$ \\
\hline A year ago or more & 66.0 & $38.2(35.2-41.3)$ & $46.0(44.0-48.1)$ \\
\hline Never used dental services & 1.4 & $27.1(18.0-38.8)$ & $51.0(41.1-60.7)$ \\
\hline \multicolumn{4}{|l|}{ Use of toothbrush } \\
\hline No & 3.2 & $69.5(62.8-75.5)$ & $39.3(32.2-46.7)$ \\
\hline Yes & 96.8 & $28.1(25.8-30.5)$ & $45.6(44.0-47.3)$ \\
\hline \multicolumn{4}{|l|}{ Use of toothpaste } \\
\hline No & 2.8 & $65.0(57.9-71.5)$ & $40.2(31.6-49.4)$ \\
\hline Yes & 97.2 & $28.4(26.0-30.9)$ & $45.6(44.0-47.2)$ \\
\hline \multicolumn{4}{|l|}{ Use of dental floss } \\
\hline No & 61.6 & $44.6(41.3-47.9)$ & $45.5(43.7-47.4)$ \\
\hline Yes & 38.4 & $05.1(04.0-06.4)$ & $45.3(42.9-47.8)$ \\
\hline
\end{tabular}

$95 \% \mathrm{Cl}: 95 \%$ of confidence interval. 
participants reported a need for dental treatment (56.2\%) and (66\%) had not used dental care in the last year. A large part of the sample reported brushing their teeth and using a toothbrush. However, $(61.6 \%)$ did not use dental floss. The prevalence of poor self-reported oral health was similar between the categories, with a greater discrepancy in the self-perceived treatment need. Furthermore, the prevalence of edentulism was higher among the most disadvantaged groups.

Table 2 shows the population distribution and dependent variables according to socioeconomic characteristics. It is possible to observe that when the individual income variable is used, most of the sample is in the poorest quintiles, while the other variables have a more homogeneous distribution. The prevalence of poor self-reported oral health and edentulism was higher among individuals in the poorest quintile, compared with those in the richest quintile.

Poisson regression models assessing the association between each socioeconomic indicator and the results are shown in Table 3 . The associations were adjusted by sex, age, race, education, treatment need, use of dental services, and use of toothbrushes, toothpaste, and dental floss. The individual income indicator was not statistically associated with edentulism and self-perception of oral health. When using per capita household income, only selfreported oral health was statistically associated. Individuals in the richest quintile showed a $12 \%$ lower prevalence of poor self-reported oral health [PR: 0.88 (95\%CI: 0.78-0.98)], when compared to the poorest quintile of per capita household income.

Table 2. Weighted Sample socioeconomic characteristics, prevalence and crude prevalence ratios of edentulism and poor selfperception of oral health among older adults at baseline of the Brazilian Longitudinal Study of Aging.

\begin{tabular}{|c|c|c|c|}
\hline \multirow{2}{*}{ Socioeconomic variables } & Weighted & Edentulism & Poor self-reported of oral health \\
\hline & $\%$ & Prevalence $(95 \% \mathrm{Cl})$ & Prevalence $(95 \% \mathrm{Cl})$ \\
\hline \multicolumn{4}{|l|}{ Individual income } \\
\hline 1st quintile (poorest) & 23.0 & $24.0(21.1-27.2)$ & $49.7(46.6-52.8)$ \\
\hline 2nd quintile & 22.5 & $42.4(38.8-46.0)$ & $44.3(41.7-47.1)$ \\
\hline 3rd quintile & 13.5 & $38.5(34.0-43.2)$ & $44.8(41.7-47.9)$ \\
\hline 4th quintile & 19.8 & $30.2(26.9-33.7)$ & $46.8(44.2-49.3)$ \\
\hline 5th quintile (richest) & 21.2 & $16.3(14.0-18.8)$ & $41.0(38.3-43.9)$ \\
\hline Q1-Q5 & & 7.7 & 8.7 \\
\hline \multicolumn{4}{|c|}{ Per capita household income } \\
\hline 1st quintile (poorest) & 19.5 & $30.5(27.7-33.6)$ & $51.3(47.3-55.3)$ \\
\hline 2nd quintile & 19.1 & $33.9(30.3-37.7)$ & $48.4(45.1-51.6)$ \\
\hline 3rd quintile & 19.4 & $38.0(34.1-42.0)$ & $45.3(42.3-48.3)$ \\
\hline 4th quintile & 20.9 & $26.8(23.5-30.4)$ & $45.6(42.7-48.5)$ \\
\hline 5th quintile (richest) & 21.1 & $20.2(17.7-23.0)$ & $37.2(34.8-39.7)$ \\
\hline QI-Q5 & & 10.3 & 14.1 \\
\hline \multicolumn{4}{|l|}{ Wealth } \\
\hline 1st quintile (poorest) & 20.0 & $42.0(37.7-46.5)$ & $48.4(45.8-51.1)$ \\
\hline 2nd quintile & 20.0 & $39.4(35.7-43.2)$ & $49.1(45.9-52.3)$ \\
\hline 3rd quintile & 20.0 & 29.7 (26.7-32.8) & $45.7(43.0-48.4)$ \\
\hline 4th quintile & 20.1 & $23.8(20.9-26.9)$ & $45.7(42.2-49.2)$ \\
\hline 5th quintile (richest) & 19.9 & $13.6(11.1-16.5)$ & $38.1(35.6-40.6)$ \\
\hline Q1-Q5 & & 28.4 & 10.3 \\
\hline
\end{tabular}

$95 \% \mathrm{Cl}: 95 \%$ of confidence interval. 
Table 3. Weighted adjusted prevalence ratios of socioeconomic variables with edentulism and poor self-perception of oral health among older adults at baseline of the Brazilian Longitudinal Study of Aging, using Poisson regression models.

\begin{tabular}{|c|c|c|}
\hline \multirow{2}{*}{ Socioeconomic variables } & Edentulism & Poor self-reported oral health \\
\hline & $\mathrm{PR}^{*}(95 \% \mathrm{Cl})$ & $\mathrm{PR}^{*}(95 \% \mathrm{Cl})$ \\
\hline \multicolumn{3}{|l|}{ Individual income } \\
\hline 1st quintile (poorest) & 1 & 1 \\
\hline 2nd quintile & $0.98(0.88-1.10)$ & $1.02(0.94-1.10)$ \\
\hline 3rd quintile & $0.94(0.83-1.06)$ & $1.02(0.94-1.10)$ \\
\hline 4th quintile & $0.95(0.85-1.05)$ & $1.01(0.95-1.09)$ \\
\hline 5th quintile (richest & $0.87(0.75-1.00)$ & $0.92(0.83-1.02)$ \\
\hline \multicolumn{3}{|c|}{ Per capita household income } \\
\hline 1st quintile (poorest) & 1 & 1 \\
\hline 2nd quintile & $1.06(0.96-1.17)$ & $0.98(0.91-1.06)$ \\
\hline 3rd quintile & $1.01(0.89-1.14)$ & $0.98(0.89-1.09)$ \\
\hline 4th quintile & $0.96(0.85-1.07)$ & $0.99(0.91-1.08)$ \\
\hline 5th quintile (richest) & $0.94(0.83-1.07)$ & $0.88(0.78-0.98)$ \\
\hline \multicolumn{3}{|l|}{ Wealth } \\
\hline 1st quintile (poorest) & 1 & 1 \\
\hline 2nd quintile & $1.03(0.94-1.13)$ & $1.08(1.01-1.14)$ \\
\hline 3rd quintile & $0.93(0.83-1.04)$ & $0.98(0.90-1.06)$ \\
\hline 4 th quintile & $0.95(0.85-1.06)$ & $0.97(0.89-1.06)$ \\
\hline 5st quintile (richest) & $0.78(0.64-0.94)$ & $0.85(0.78 .0 .93)$ \\
\hline
\end{tabular}

PR: prevalence ratio; $95 \% \mathrm{Cl}$ : 95\% of confidence interval; *Adjusted for sex, age, race/ethnicity, education, need for treatment, use of dental services, and use of toothbrushes, toothpaste, and dental floss.

There was no statistical association between per capita household income and edentulism. When the wealth index was used, a statistical association was found with both oral health outcomes. Individuals in the richest quintile of wealth showed a $22 \%$ lower prevalence of edentulism [PR: 0.78 (95\%CI: 0.64-0.94)] and $15 \%$ lower in reporting poor oral health [PR: 0.85 (95\% CI: 0.78-0.93)], both relative to the poorest quintile of wealth.

Regarding absolute inequality measures, for edentulism, the wealth index showed the highest absolute inequality (-28.4 p.p), followed by per capita household income (-10.3 p.p), and individual income (-7.7 p.p). When considering self-reported oral health, per capita household income presented the greatest absolute inequality (-14.1 p.p), followed by wealth index (-10.3 p.p.) and individual income (-8.7 p.p). Negative values suggest that the outcome is more prevalent in the most disadvantaged groups, for example, the poorest group. ${ }^{27}$

\section{Discussion}

We analyzed the performance of different socioeconomic status indicators (individual income, per capita household income, and wealth index) when associated with the oral health status of adults over 50 years old. Previous studies have researched different measures of socioeconomic status and their influence on general health, including inequalities in maternal coverage and mortality $y^{15,16,26}$ However, few studies have evaluated different socioeconomic measures to assess inequalities in health outcomes in developing countries, ${ }^{10,16}$ and no studies have considered oral health conditions. Therefore, to our knowledge, our study is the first to assess socioeconomic indicators to identify oral health disparities in countries facing inequalities.

Although there is still a discrepancy between consumption data, such as individual income or 
per capita household income, and asset data, such as the wealth index, there is evidence supporting the use of the wealth index (for measurement) when compared to volatile and inaccurate consumption indicators. ${ }^{28}$ Efforts to gather wealth information as part of administrative collection data can be a complex process. However, the explanatory power of socioeconomic status indicators based on wealth seems to have a better quality relative to more conventional indicators. ${ }^{15}$ Moreover, individual income or per capita household income may be difficult to collect. Saying how much money they earn can make an individual feel uncomfortable for a variety of reasons, such as fear of theft or taxation..$^{29}$ Therefore, data on assets are considered easier to obtain and people might be more willing to respond accurately. ${ }^{28,30}$

The data collection for the wealth index is based on a series of durable assets and information of housing characteristics and access to basic services. ${ }^{31}$ The selected items are already included in most surveys because of their potential health influence (for example, the ownership of a TV, which can serve as a source of information regarding health habits ${ }^{16}$ ). It is also necessary to highlight that the selection of assets for a wealth index is not a simple task. There are items that are clearly markers of wealthy households, such as the presence of a housekeeper. Other goods have an approximately linear relationship with the quintiles, such as cars and freezers. Other goods are almost universal, such as refrigerators and color televisions. ${ }^{32}$ It is important that all these groups of assets be included to maintain the indicator's discriminatory capacity. However, the inclusion of assets with very similar behavior does not present a substantial discriminatory gain. ${ }^{32}$

The wealth index does not represent current income, rather, it represents a family's permanent consumption capacity. ${ }^{32}$ It is an indicator of financial resources accumulated over time (including inheritances), and the patterning of wealth in old age might differ substantially from income patterns. ${ }^{33}$ This might suggest that wealth is a more stable measure of socioeconomic position because current income is subject to significant fluctuations when recorded in a relatively short period. ${ }^{32}$
Regarding the use of per capita household income, a problem in using it is that family members may have unequal access to family income. ${ }^{15}$ That is, people can feel a socioeconomic status that they do not enjoy. A second limitation inherent to the use of this variable is that it may be an inadequate representation of the retiree's standard of living. It may not reflect the financial resources available and may disregard the accumulated value effects of a lifetime of deprivation or privilege. ${ }^{15}$

Regarding individual income, some studies show that when income levels and basic needs go beyond the poverty line, individual income alone does not explain health inequalities. ${ }^{34}$ Also, how much a person earns may not quantify his lifestyle, which can be supported by other family members. For this reason, we believe that individual income did not prove to be a good socioeconomic indicator of inequalities in individuals' oral health.

Our findings showed a great disparity in oral disease prevalence, especially among the population's extreme extracts, where the richest portion had positive results and the poorest portion had negative results. This is in line with studies that show a disadvantage in oral health among the least socioeconomically favored. ${ }^{4,35}$ This socioeconomic inequality is also demonstrated between countries at different development levels, such as Brazil, where population social disparities are more evident. ${ }^{36}$ Socioeconomic status has been recognized as a risk factor for morbidity and mortality varying over time by culture and age group, with the elderly population being the most affected. ${ }^{37}$ In the same way that aging causes impasses in general health, many elderly people have a range of oral problems that are affected by common risk factors with systemic diseases. ${ }^{38}$ Health inequalities in the elderly have received relatively little attention, perhaps partly because of measurement problems. Measuring socioeconomic status in older age groups is necessary for research and oral health policy for an expanding but still marginalized population. ${ }^{39}$

Absolute inequalities, once identified, allow observation of patterns of population inequality. We found that individuals aged 50 years or older living in Brazil who have better oral health conditions 
also have a higher socioeconomic level. In addition, we observed that the use of different indicators produces different inequalities in the population and it is important that more studies are carried out to assess other differences, such as geographic regions, ethnic groups, age groups, and sex/gender categories. ${ }^{26}$ Moreover, the visualization of these inequalities is useful for formulating strategies to promote equality between these groups, prioritizing the improvement of indicators among the most disadvantaged, and favoring the progress of national indicators. As far as we know, there is no study evaluating which indicator is the most adequate to identify scenarios of socioeconomic inequalities in Brazilian population's oral health.

The ELSI-Brazil is part of an international network of large longitudinal studies on aging. These studies are called "Family Health and Retirement Studies." Although these studies are independent, meeting the demands and particularities of each country, they seek to adopt a common methodology. This makes it possible to carry out comparable studies in different countries. However, to our knowledge, there are no similar investigations in distinct contexts. Carrying out said studies could be a way to verify the relationship between economic indicators and oral health inequities, allowing international comparisons.

This study had some limitations. The crosssectional design limited the scope for causal inferences, highlighting the need for prospective studies. In addition, this study was based entirely on self-reported data, so a possible memory bias may have occurred. However, this is not expected to be significant, as self-reported data is considered a valid oral health measure. ${ }^{20} \mathrm{We}$ also emphasize that no single measure will be ideal for all studies and contexts; the strengths and limitations of a given indicator can vary depending on the specific research question. Other variables could be associated with the investigated events. However, the model was adjusted for the variables most commonly found in the literature., ${ }^{713,21}$ Therefore, it is expected that other associations will not significantly interfere with the final results.

\section{Conclusion}

The Wealth index was the socioeconomic indicator that better identified oral health inequalities in Brazilian adults over 50 years old. Despite scientific challenges and the difficulty of socioeconomic indicator metrics, further research in this area is critical to measure, promote, and improve oral public health.

\section{Acknowledgment}

This study was financed in part by the Coordenação de Aperfeiçoamento de Pessoal de Nível Superior Brasil (Capes) - Finance Code 001.

\section{References}

1. Colombo DG. Closing the gap in a generation: health equity through action on the social determinants of health. Final report of the Commission on Social Determinants of Health. Rev Direito Sanit. 2010;10(3):253. https://doi.org/10.11606/issn.2316-9044.v10i3p253-266

2. Krieger N. Theories for social epidemiology in the 21st century: an ecosocial perspective. Int J Epidemiol. 2001 Aug;30(4):668-77. https://doi.org/10.1093/ije/30.4.668

3. Braveman P, Gottlieb L. The social determinants of health: it's time to consider the causes of the causes. Public Health Rep. 2014 Jan-Feb;129(1 Suppl 2):19-31. https://doi.org/10.1177/00333549141291S206

4. Marcenes W, Kassebaum NJ, Bernabé E, Flaxman A, Naghavi M, Lopez A, et al. Global burden of oral conditions in 1990-2010: a systematic analysis. J Dent Res. 2013 Jul;92(7):592-7. https://doi.org/10.1177/0022034513490168

5. Watt RG, Heilmann A, Listl S, Peres MA. London Charter on Oral Health Inequalities. J Dent Res. 2016 Mar;95(3):245-7. https://doi.org/10.1177/0022034515622198

6. Kassebaum NJ, Smith AG, Bernabé E, Fleming TD, Reynolds AE, Vos T, et al. Global, regional, and national prevalence, incidence, and disability-adjusted life years for oral conditions for 195 countries, 1990-2015: a systematic analysis for the global burden of diseases, injuries, and risk factors. J Dent Res. 2017 Apr;96(4):380-7. https://doi.org/10.1177/0022034517693566 
7. Watt RG, Sheiham A. Integrating the common risk factor approach into a social determinants framework. Community Dent Oral Epidemiol. 2012 Aug;40(4):289-96. https://doi.org/10.1111/j.1600-0528.2012.00680.x

8. Smith GD, Chaturvedi N, Harding S, Nazroo J, Williams R. Ethnic inequalities in health: A review of UK epidemiological evidence. Crit Public Health. 2000;10(4):375-408. https://doi.org/10.1080/09581590010005331

9. Sheiham A, Watt RG. The common risk factor approach: a rational basis for promoting oral health. Commun Dent Oral Epidemiol. 2000 Dec;28(6):399-406. https://doi.org/10.1034/j.1600-0528.2000.028006399.x

10. Galobardes B, Shaw M, Lawlor DA, Lynch JW, Davey Smith G. Indicators of socioeconomic position (part 1). J Epidemiol Community Health. 2006 Jan;60(1):7-12. https://doi.org/10.1136/jech.2004.023531

11. Herkrath FJ, Vettore MV, Werneck GL. Contextual and individual factors associated with dental services utilisation by Brazilian adults: a multilevel analysis. PLoS ONE. 2018;13(2):e0192771. https://doi.org/10.1371/journal.pone.0192771

12. Bastos TF, Medina L PB, Sousa NF S, Lima MG, Malta DC, Barros MB. Income inequalities in oral health and access to dental services in the Brazilian population: National Health Survey, 2013. Rev Bras Epidemiol. 2019;22(suppl 2):E190015.SUPL.2. https://doi.org/10.1590/1980-549720190015.supl.2

13. Andrade FB, Antunes JL, Souza Junior PR, Lima-Costa MF, Oliveira C. Life course socioeconomic inequalities and oral health status in later life: ELSI-Brazil. Rev Saude Publica. 2018 Oct;52(52 Suppl 2):7s. https://doi.org/10.11606/s1518-8787.2018052000628

14. Rocha RA, Goes PS. [Comparison of access to Oral Health Services between areas covered and not covered by the Family Health Program in Campina Grande, Paraíba State, Brazil]. Cad Saude Publica. 2008 Dec;24(12):2871-80. Portuguese. https://doi.org/10.1590/S0102-311X2008001200016

15. Daly MC, Duncan GJ, McDonough P, Williams DR. Optimal indicators of socioeconomic status for health research. Am J Public Health. 2002 Jul;92(7):1151-7. https://doi.org/10.2105/AJPH.92.7.1151

16. Howe LD, Galobardes B, Matijasevich A, Gordon D, Johnston D, Onwujekwe O, et al. Measuring socio-economic position for epidemiological studies in low- and middle-income countries: a methods of measurement in epidemiology paper. Int J Epidemiol. 2012 Jun;41(3):871-86. https://doi.org/10.1093/ije/dys037

17. Fry K, Firestone R, Chakraborty N. Measuring equity with nationally representative wealth, quintiles. Washington, DC: PSI; 2014.

18. Lima-Costa MF, Andrade FB, Souza PR Jr, Neri AL, Duarte YA, Castro-Costa E, et al. The Brazilian longitudinal study of aging (ELSIBrazil): objectives and design. Am J Epidemiol. 2018 Jul;187(7):1345-53. https://doi.org/10.1093/aje/kwx387

19. Vasconcelos LC, Prado Júnior RR, Teles JB, Mendes RF. [Self-perceived oral health among elderly individuals in a medium-sized city in Northeast Brazil]. Cad Saude Publica. 2012 Jun;28(6):1101-10. Portuguese. https://doi.org/10.1590/S0102-311X2012000600009

20. Locker D, Mscn EW, Jokovic A. What do older adults' global self-ratings of oral health measure? J Public Health Dent. 2005;65(3):146-52. https://doi.org/10.1111/j.1752-7325.2005.tb02804.x

21. Bassim CW, MacEntee MI, Nazmul S, Bedard C, Liu S, Ma J, et al. Self-reported oral health at baseline of the Canadian Longitudinal Study on Aging. Community Dent Oral Epidemiol. 2019;48(1):12506. https://doi.org/10.1111/cdoe.12506

22. Sousa JL, Henriques A, Silva ZP, Severo M, Silva S. [Socioeconomic position and self-rated oral health in Brazil: results of the Brazilian National Health Survey]. Cad Saude Publica. 2019;35(6):e00099518. Portuguese. https://doi.org/10.1590/0102-311x00099518

23. Pollack CE, Chideya S, Cubbin C, Williams B, Dekker M, Braveman P. Should health studies measure wealth? A systematic review. Am J Prev Med. 2007 Sep;33(3):250-64. https://doi.org/10.1016/i.amepre.2007.04.033

24. Baumgarten A, Bastos JL, Toassi RF, Hilgert JB, Hugo FN, Celeste RK. Discrimination, gender and self-reported aesthetic problems among Brazilian Adults. Community Dent Oral Epidemiol. 2018 Feb;46(1):24-9. https://doi.org/10.1111/cdoe.12324

25. Gouvêa GR, Bulgareli JV, David LL, Ambrosano GM, Cortellazzi KL, Guerra LM, et al. Variables associated with the oral impact on daily performance of adults in the state of São Paulo: a population-based study. PLoS One. 2018 Sep;13(9):e0203777. https://doi.org/10.1371/journal.pone.0203777

26. Barros AJ, Victora CG. Measuring coverage in $\mathrm{MNCH}$ : determining and interpreting inequalities in coverage of maternal, newborn, and child health interventions. PLoS Med. 2013;10(5):e1001390. https://doi.org/10.1371/journal.pmed.1001390

27. Silva IC, Restarepo-Mendez MC, Costa JC, Ewerling F, Hellwig F, Ferreira LZ, et al. Measurement of social inequalities in health: concepts and methodological approaches in the Brazilian context. Epidemiol Serv Saude. 2018;27(1):e000100017. https://doi.org/10.5123/S1679-49742018000100017

28. Wall M, Johnston D. Counting Heads or counting televisions: can asset-based measures of welfare assist policy-makers in Russia? J Hum Dev. 2008;9(1):131-47. https://doi.org/10.1080/14649880701811468

29. Moore JC, Stinson LL, Welniak EJ. Income measurement error in surveys: a review. J Oficial Sttistics. 2000;16(4):331-61.

30. Rutstein SO, Johnson K. The DHS wealth index. DHS Comparative Reports Calverton: ORC Macro; 2004. (DHS comparative reports, v. 6).

31. Vyas S, Kumaranayake L. Constructing socio-economic status indices: how to use principal components analysis. Health Policy Plan. 2006 Nov;21(6):459-68. https://doi.org/10.1093/heapol/czl029 
Impact of adopting different socioeconomic indicators in older adults' oral health research

32. Ewerling F, Barros AJ. After 10 years, how do changes in asset ownership affect the Indicador Econômico Nacional? Rev Saude Publica. 2017 Mar;51(0):10. https://doi.org/10.1590/s1518-8787.2017051006517

33. Darin-Mattsson A, Fors S, Kåreholt I. Different indicators of socioeconomic status and their relative importance as determinants of health in old age. Int J Equity Health. 2017 Dec;16(1):173. https://doi.org/10.1590/S1518-8787.2017051006517

34. Marmot M. The influence of income on health: views of an epidemiologist. Health Aff (Millwood). 2002 Mar-Apr;21 (2):31-46. https://doi.org/10.1377/hlthaff.21.2.31

35. Sfreddo CS, Moreira CH, Nicolau B, Ortiz FR, Ardenghi TM. Socioeconomic inequalities in oral health-related quality of life in adolescents: a cohort study. Qual Life Res. 2019 Sep;28(9):2491-500. https://doi.org/10.1007/s11136-019-02229-2

36. Sheiham A, Alexander D, Cohen L, Marinho V, Moysés S, Petersen PE, et al. Global oral health inequalities: task group: implementation and delivery of oral health strategies. Adv Dent Res. 2011 May;23(2):259-67. https://doi.org/10.1177/0022034511402084

37. Berkman CS, Gurland BJ. The relationship among income, other socioeconomic indicators, and functional level in older persons. J Aging Health. 1998 Feb;10(1):81-98. https://doi.org/10.1177/089826439801000105

38. Kossioni AE, Hajto-Bryk J, Maggi S, McKenna G, Petrovic M, Roller-Wirnsberger RE, et al. An expert opinion from the European College of Gerodontology and the European Geriatric Medicine Society: European policy recommendations on oral health in older adults. J Am Geriatr Soc. 2018 Mar;66(3):609-13. https://doi.org/10.1111/igs.15191

39. Grundy E, Holt G. The socioeconomic status of older adults: how should we measure it in studies of health inequalities? J Epidemiol Community Health. 2001 Dec;55(12):895-904. https://doi.org/10.1136/jech.55.12.895 